\title{
Frost Resistance of Concrete with Different Strength Grades and Mineral Admixtures
}

\author{
Kefeng $\operatorname{Tan}^{1}$, John M. Nichols² \\ ${ }^{1}$ Department of the Materials Science School at the South West University of Science and Technology, Mianyang \\ City, Sichuan Province, PRC \\ ${ }^{2}$ Department of Construction Science, College of Architecture, Texas A\&M University, College Station, TX, \\ 77840, USA \\ Email: jm-nichols@tamu.edu
}

\begin{abstract}
This research investigated the effect of water to cement ratio and mineral admixtures on the frost resistance of concrete. The test method used is based on the ASTM Standard C666 Standard Test Method for Resistance of Concrete to Rapid Freezing and Thawing. Ten mix designs were used for the experimental testing. The test results show that the frost resistance of concrete increases as the water to cement ratio decreases. Actually, for low water to cement ratio or high strength concrete, the frost resistance is excellent even without adding air-entraining agent. For the medium or high water to cement ratio concrete however, incorporating an air-entraining agent is necessary to improve their frost resistance. Incorporation of silica fume improves the frost resistance of concrete, whilst adding fly ash into concrete makes the frost resistance worse. The objective of the research is to determine if a zero air-entrained concrete is durable to freeze thaw cycles.
\end{abstract}

Keywords: Concrete; frost resistance; w/c ratio; mineral admixture; air entraining agent.

\section{Introduction}

Humans have slowly pushed the envelope in moving into extremely inhospitable places to live in every increasing numbers. The relative cheap availability of energy with the development of reverse cycle air conditioning has made this transition smooth and possible. The inside of the Artic shelter may be warm, but the outside is still subjected to freeze and thaw cycles. Freezing and thawing would not be a problem except for the change in volume that water undergoes as it freezes. To prevent damage to concrete by repeated cycles of freezing and thawing, air should be deliberately entrained into concrete using an air-entraining agent. While the entrained air increases durability, it also decreases concrete strength, and so for this reason, air entrainment is undesirable in High Strength Concrete (HSC) [1]. Many researchers question the need for air entrainment in $\operatorname{HSC}[2,3,4,5,6]$, however, a significant number of researchers still recommend the use of air entrainment for improved durability for concrete subjected to freeze thaw $[1,5,6,7,8]$.

Research is required to determine whether a frost resistant HSC can be produced without any air entrainment. The purpose of the research is to consider the impact of air entrainment on normal and moderately high strength concretes, up to $70 \mathrm{MPa}$, that can be used in concrete filled steel tubes systems or for reinforced concrete structures that will be subjected to freeze and thaw situations.

This paper outlines the literature relevant to this work, provides a methods section, outlines and summarizes the results and the key findings, and provides a conclusion.

\section{$2 \quad$ Literature Review}

Water is a challenging material because of the low compressibility and the expansion on freezing. The freeze to thaw cycle is responsible for significant damage in the human and natural environments. Figure 1 shows the density of $\mathrm{H}_{2} \mathrm{O}$ at varying temperatures from -175 to $100{ }^{\circ} \mathrm{C}$. The critical point is the change in density in moving from water to ice in the range of -1 to $4{ }^{\circ} \mathrm{C}$. Figure 2 illustrates the volume of $1000 \mathrm{~kg}$ of water at varying temperatures. The critical change is the nine percent increase near the triple point as water changes to ice. 
Cohen, Zhou and Dolch [1] reviewed the performance of non-air entrained high strength concrete and concluded that air entrainment improved the performance, but that silica fume did not improve the performance. Hooton [2] showed that silica fume improved the physical properties of pastes, mortars and concretes. Lessard, Baalbaki and Aitcin [3] investigated the mix design of air entrained high performance concrete. Li, Langan and Ward [4] showed that the water to cement content was the critical item for durability against freeze thaw cycles. Marchand et al. [5] considered the frost durability of high strength concretes. Pigeon et al. [6] showed that for a low water to cement ratio for high performance concretes air entraining was not required for durability when tested in accordance with the ASTM Standard Test [7]. Fagerlund [8] confirmed the earlier findings for high performance concrete subjected to freeze thaw cycles as did Zia and Hansen [9].

Finally, in 2017, Yu, Ma and Yan [10] published an equation to determine the freeze thaw damage in concrete. This work can be traced from Powers [11] who started with the observation that a 9\% increase in volume can occur for the freezing water and moved onto develop the theory. Yu, Ma and Yan [10] thoroughly outlined the theory, which is not repeated here aside from the critical equation for the maximum hydrostatic pressure being:

$$
p_{\max }=\frac{1}{89 k} \frac{d w_{f}}{d \theta} \frac{d \theta}{d t} d^{2}
$$

Here, 89 is derived from the expansion divided by $8, k$ is the permeability of the frozen material, $d$ represents the distance between air voids, typically in the order of $1 \mathrm{~mm}, \frac{d w_{f}}{d \theta}$ represents the freezing rate and $\frac{d \theta}{d t}$ represents the cooling rate.

The second damaging method is osmotic pressure from organic chemicals mixed with water. The relevant equation for this effect on the concrete is

$$
\Delta P=\frac{R T}{V} \ln \frac{p_{w}}{p_{i}}
$$

Here, $T$ is the temperature in Kelvin, $\Delta P$ is the osmotic pressure difference in Pascals, $p_{w}$ is the vapour pressure of the gel water, $p_{i}$ is the vapour pressure of the ice and $V$ is the molar volume of water being $0.018 \mathrm{l} / \mathrm{mol}$.

The next stage is to determine the damage parameter, typically defined as:

$$
D=1-\frac{\bar{E}}{E}, 0<D \leq 1
$$

Here taken from Krajcinovic [12], where $D$ is the damage parameter, $E$ is the initial Young's Modulus and $\bar{E}$ is the measured Young's modulus after damage occurs. In some senses, the damaged modulus is termed the measured modulus. Yu, Ma and Yan [10] termed the modulus as dynamic, but in reality this is a misnomer, although Baker refers to it [13]. Refer to Yu, Ma and Yan [10] for full details of the derivation, which is not repeated here.

\section{$3 \quad$ Methods}

ASTM C666 [7] outlines the test method prescribed for this experimental work. A similar standard exists in China [14]. The cement used was Grade 42.5 MPa Portland cement. Crushed gravel with a maximum diameter of $25 \mathrm{~mm}$ was used as coarse aggregate. Natural sand was used as fine aggregate. A naphthalene-based dispersing agent was used to get a workable fresh concrete. Table 1 summarizes the composition of eight mixes included in the test program. The mixes are designated 1 to 5 and AE1, AE2, and AE5.

The concrete specimens for frost resistance test are $40 \times 40 \times 160 \mathrm{~mm}$ prisms cured in a standard moisture room for 28 days. The specimens for compressive strength test are $100 \times 100 \mathrm{~mm}$ cube ones, which are in accordance with normal Chinese practice.

The effect of air entrainment on frost resistance of High Strength concrete was experimentally investigated using eight samples. Sample mixes numbered 1 to 5 were free of air-entraining agent, and 
mixes 3 and 4 were made with silica fume and fly ash respectively. Sample mixes denoted as AE1, AE2 and AE5 were made with an air entraining agent.

The frost resistance testing was conducted using a DR-2 accelerated freezing-thawing apparatus in accordance with the requirements of ASTM C666 (9).

A DT-10 stricken dynamic modulus measuring apparatus provided the dynamic modulus of each specimen. Measurements occurred at the start of the experiments and then every 25 freeze thaw cycles. Each resultant modulus value is the average of 3 specimens.

\section{$4 \quad$ Results and Discussion}

The test method used in this experimental work is an accepted international test method used in the USA and China. The experimental work used the standard method of varying some elements of the mix design to determine the result with the least damage from the freeze thaw cycles in accordance with accepted testing and statistical theory [15].

Table 1 lists the components of the various concrete mixes and provides the results for the compression testing for the characteristic strength.

The first stage of the experimental work is to test a water to binder ratio of 0.27 , which is a typical mix for some uses. Tests 1 and AE1 were used to determine the results for this water to binder ratio. Sample set 1 had no air entraining and AE1 had 0.0600 air entraining agent added to the mix. Table 2 lists the dynamic modulus results for the two sample sets. Figure 3 shows the plot of the test results. The results show that for an HSC with a w/c of 0.27 , a $96.1 \%$ dynamic modulus remains after 300 freezing thawing cycles thus showing very high frost resistance. The Air Entraining agent does not reduce the Dynamic Modulus when compared to the standard sample.

As the two data sets commence at $100 \%$, a simple test of dividing the change in modulus by the number of cycles provides a coarse indicator of the slope. A Students t Test analysis of the two sets of results for the plain and the air entrained concrete shows that the two sets of results are not statistically different as measured at the $5 \%$ level, with a t-Stat of 0.50 . This is a relatively course and brutal statistical test for the data, when in reality the objective is to seek some acceptance criteria, such as after 300 cycles the damage modulus will be greater than $90 \%$ determined through engineering experience. In this case, the two materials meet the acceptance criteria. The air entrained sample suffered a lower level of damage when compared to the plain concrete, but it cannot be judged statistically significant.

The interesting question results from the observation that there is a minimal effect of air entraining agent for the low water to cement ratios of 0.27 . The question can be phrased as:

Is the water to cement ratio too low to allow further improvement due to the air entraining agent?

A water to cement ratio of 0.27 is 3 to $8 \%$ below the nominal level of 0.3 to 0.35 required for complete hydration of the cement. The result of $59 \mathrm{MPa}$ for the air entrained sample AE1 is lower than the plain sample 1 at $69 \mathrm{MPa}$. It is suggested that Sample 1 may have a better permeability for water once the samples were stored in the moist environment, resulting in the higher strength. There is no statistically significant difference in the dynamic modulus test, but Figure 6 strongly suggests the AE1 should have performed better and Figure 8 suggests that Sample 1 has higher strength than a linear model would suggest. The limited number of samples for random variables may be the real problem and further testing is recommended at this water to cement ratio.

The second result set is for a water to cement ratio of 0.4 , being mid-range in the samples. Test set 2 and AE2 were used to determine the dynamic modulus for this water to cement ratio. Figure 4 shows the dynamic modulus results for a water to cement ratio of 0.4 . The results for sample 2 show that for an HSC with middle range w/c (0.40), the dynamic modulus decreases to $51.2 \%$ and $25.5 \%$ respectively after 150 and 200 cycles. The result for the AE2 sample set with the air entraining agent is $91.5 \%$ at 300 cycles. A Students t Test analysis of the two sets of results for the plain and the air entrained concrete shows that the two sets of results are statistically different as measured at the $5 \%$ level, with a t-Stat of 2.68. The air entrained sample suffered a lower level of damage when compared to the plain concrete. Again, assuming a simple acceptance criterion of $90 \%$ the AE2 sample passes. 
The third result set is for a water to cement ratio of 0.55 , being high range. Test set 5 and AE5 were used to determine the dynamic modulus for this water to cement ratio. Figure 5 shows the dynamic modulus results for these samples. For sample 5 concrete when the $\mathrm{w} / \mathrm{c}$ ratio is 0.55 the dynamic modulus decreases to $52.7 \%$ and $20.0 \%$ respectively after 25 and 75 cycles. Sample set AE5 with air entraining agent has a better damage modulus at a full 300 cycles, with a final result for the AE5 sample of $93.2 \%$. A Students t Test analysis of the two sets of results for the plain and the air entrained concrete shows that the two sets of results are statistically different as measured at the $5 \%$ level, with a t-Stat of 3.09. The air entrained sample suffered a lower level of damage when compared to the plain concrete. Again, assuming a simple acceptance criterion of $90 \%$ the AE5 sample passes.

The next stage in the analysis is a comparison between plain and air-entrained concretes for the three water to cement ratios at a constant number of cycles. The standard test for dynamic modulus for pure water cites failure as being at about $20 \%$ of the original dynamic modulus at a maximum of 300 cycles. Figure 6 shows the dynamic modulus for a cycle count of 75 for non-air entrained concrete and air entrained concrete. Clearly the air entrainment improves the dynamic modulus when compared to pure cement concrete. The increase in the water cement ratio causes a significant loss in stiffness as shown in the figure for the non-air entrained concrete and a smaller loss for the other type.

Figure 7 shows a plot of the cycle count at failure against water to cement ratio for the non-air entrained samples 1, 2 and 5. The linear regression equation that fits this data is:

$$
y=518.76-804.33 x
$$

Here $x$ is the water to cement ratio and $y$ is the cycle count at failure or 300 as a maximum. The regression co-efficient is 0.995 . A higher water to cement ratio yields a lower durability modulus for a given number of cycles.

The final experimental work was the use of silica fume and fly-ash in the mix. Mix 3 used silica fume and Mix 4 used fly-ash with water to binder ratio of 0.4 as for sample 2. Figure 8 shows the results for a water to cement ratio of 0.4 for the non-air entrained cement, silica fume and fly -ash. The results show that only silica fume provides an acceptable dynamic modulus at this water to cement ratio, with a modulus of 64 at 300 cycles.

Figure 9 shows the plot of the compressive strengths for the concrete plotted against the water to cement ratios and for the different air entraining agents. The results as expected show a significant drop in strength as the water to cement ratio increases.

\section{Conclusions}

Structural reliability is a leading concern for the development of new and the refurbishment of old structures. The standard theory for structural reliability opines that the best structural solution at the lowest cost provides one measure of acceptance. A significant expenditure on structures that are subject to freeze and thaw conditions occurs around the world. A reasonable assumption, even allowing for the real issues in the use of silica fume, is that in the overall costs of construction the eight mixes used in this experimental work will have a similar cost per cubic metre. The differences will exist, but for these purposes they are not considered significant, when compared to the overall lifetime costs of a structure. With this assumption in place, a reasonable decision is to accept the concrete mix with the highest dynamic modulus after 300 tests.

On this basis, the test samples 2, 4 and 5 are considered unacceptable as they failed to reach 300 cycles of testing. Test sample 3 is eliminated as it had a result of $64.1 \%$ after 300 cycles. Of the remaining, test samples 1 and AE1 had the best results at about $96 \%$ dynamic modulus after 300 cycles. At this point the discussion is a little moot, assuming insignificant cost difference, the only difference between 1 and AE1 is the 69 to $59 \mathrm{MPa}$ difference in strength and hence one is left with the simple question of what strength is required, but a conservative engineer will usually select sample 1 for the strength reasons.

In conclusion, silica fume and fly ash should be discounted for concrete subjected to significant freeze thaw cycles without significant further research. The standard objective of lowering the water to cement ratio of improving the strength holds for this test set looking at durability and would appear to continue to be the preferred practice for a reasonable engineer. 
Further work is suggested on very high strength flowable concretes as these are the ways of the future in construction and on the low water to cement ratio concretes.

\section{References}

1. M.D. Cohen, Y. Zhou, and W.L. Dolch, Non-air-entrained high strength concrete-is it frost resistant. ACI Materials Journal, 1992. 89(4): p. 406-415.

2. R.D. Hooton, Influence of Silica Fume Replacement of Cement on Physical Properties and Resistance to Sulfate Attack, Freezing and Thawing, and Alkali-Silica Reactivity. Materials Journal, 1994. 90(2).

3. E.D. Lessard, M. Baalbaki, and P.C. Aitcin, Mix design of air entrained high performance concrete, Concrete Under Severe Conditions: Environment and loading. 1995: Chapman and Hall.

4. Y. Li, B.W. Langan, and M.A. Ward, Freezing and Thawing: Comparison Between Non-Air-Entrained and AirEntrained High-Strength Concrete. ACI Special Publication, 1994. 149.

5. J. Marchand, et al., The frost durability of high performance concrete: in Concrete under Severe Loading: Environment and loading. 1995, Chapman and Hall. Vol.1 (1995) p. 273-288.

6. M. Pigeon, et al., Freezing and thawing tests of high-strength concretes. Cement and Concrete Research, 1991. 21(5): p. 844-852.

7. ASTM International, C 666 Standard Test Method for Resistance of Concrete to Rapid Freezing and Thawing. 2015, ASTM International.

8. G. Fagerlund, Frost resistance of high performance concrete-some theoretical considerations, in Durability of High Performance Concrete, Proceedings of the RILEM International Workshop, H. Sommer, Editor. 1994, RILEM: Austria. p. 112-140.

9. P. Zia and M.R. Hansen, Durability of high performance concrete, in Pacific Rim TransTech Conference Proceedings. 1993, American Society of Civil Engineering, p. 398-404.

10.H. Yu, H. Ma, and K. Yan, An equation for determining freeze-thaw fatigue damage in concrete and a model for predicting the service life. Construction and Building Materials, 2017. 137: p. 104-116.

11.T.C. Powers, A working hypothesis for further studies of frost resistance of concrete. Journal of the American Concrete Institute, 1945. 16(4): p. 245-272.

12.D. Krajcinovic, Damage Mechanics. 1996, New York: Elsevier.

13.I.O. Baker, Treatise on Masonry Construction. Baker 1914 ed. 1914, New York: Wiley. xiv+745.

14.Ministry of Housing and Urban-Rural Development, GB/T 50082-2009 Standard for test methods of long-term performance and durability of ordinary concrete. 2009, China Academy of Building Research: Beijing.

15.R.A. Fisher, The Design of Experiments. 1971, London: Macmillan.

\section{Appendix: Tables}

Table 1. Mix proportions of concrete $\left(\mathrm{kg} / \mathrm{m}^{3}\right)$

\begin{tabular}{llllllllll}
\hline $\begin{array}{l}\text { Mix } \\
\text { no. }\end{array}$ & W/b & Cement & Sand & Gravel & $\begin{array}{l}\text { Silica } \\
\text { Fume }\end{array}$ & $\begin{array}{l}\text { Fly } \\
\text { ash }\end{array}$ & $\begin{array}{l}\text { Air Entraining } \\
\text { agent }\end{array}$ & $\begin{array}{l}\text { Air content } \\
(\%)\end{array}$ & $\begin{array}{l}\text { Concrete Strength } \\
(\mathrm{MPa}), 28 \text { days }\end{array}$ \\
\hline 1 & 0.27 & 600 & 663 & 1075 & 0 & 0 & 0 & 0.9 & 69.0 \\
2 & 0.40 & 408 & 788 & 1143 & 0 & 0 & 0 & 1.0 & 42.0 \\
3 & 0.40 & 368 & 788 & 1143 & 40 & 0 & 0 & 0.9 & 49.0 \\
4 & 0.40 & 325 & 788 & 1143 & 0 & 83 & 0 & 1.1 & 39.0 \\
5 & 0.55 & 325 & 840 & 1158 & 0 & 0 & 0 & 1.2 & 31.3 \\
AE1 & 0.27 & 600 & 663 & 1075 & 0 & 0 & 0.0600 & 4.8 & 59.3 \\
AE2 & 0.40 & 408 & 788 & 1143 & 0 & 0 & 0.0408 & 5.3 & 40.7 \\
AE5 & 0.55 & 325 & 840 & 1158 & 0 & 0 & 0.0325 & 5.7 & 27.6 \\
\hline
\end{tabular}


Table 2. Effect of air entrainment on frost resistance of concrete- dynamic modulus results expressed as percentage of untested sample

\begin{tabular}{lcccccccccccc}
\hline $\begin{array}{l}\text { Cycles } \\
\text { Mix Number. }\end{array}$ & 25 & 50 & 75 & 100 & 125 & 150 & 175 & 200 & 225 & 250 & 275 & 300 \\
\hline 1 & 96.8 & 96.5 & 96.5 & 96.1 & 96.2 & 96.2 & 96.1 & 96.1 & 96.1 & 96.1 & 96.2 & 96.1 \\
AE1 & 97.2 & 96.7 & 97 & 96.4 & 96.3 & 96.3 & 96.3 & 96.3 & 96.3 & 96.3 & 96.4 & 96.2 \\
2 & 92.6 & 90.5 & 87.6 & 81.3 & 66.9 & 51.2 & 36.1 & 25.5 & & & & \\
AE2 & 95.6 & 94.9 & 94.7 & 94.4 & 94.2 & 94.2 & 93.9 & 93.6 & 92.8 & 92.8 & 92.9 & 91.5 \\
5 & 52.7 & 37.5 & 20 & & & & & & & & & \\
AE5 & 95.1 & 94.3 & 94.6 & 94.3 & 94.3 & 94.3 & 93.8 & 93.7 & 93.5 & 93.8 & 93.5 & 93.2 \\
3 & 94.4 & 93.2 & 92.7 & 92.0 & 91.6 & 89.9 & 87.9 & 84.2 & 79.0 & 75.5 & 69.4 & 64.1 \\
4 & 93.1 & 88.6 & 81.0 & 63.4 & 50.0 & 41.2 & 33.4 & 27.7 & & & & \\
\hline
\end{tabular}

\section{Appendix: Figures}

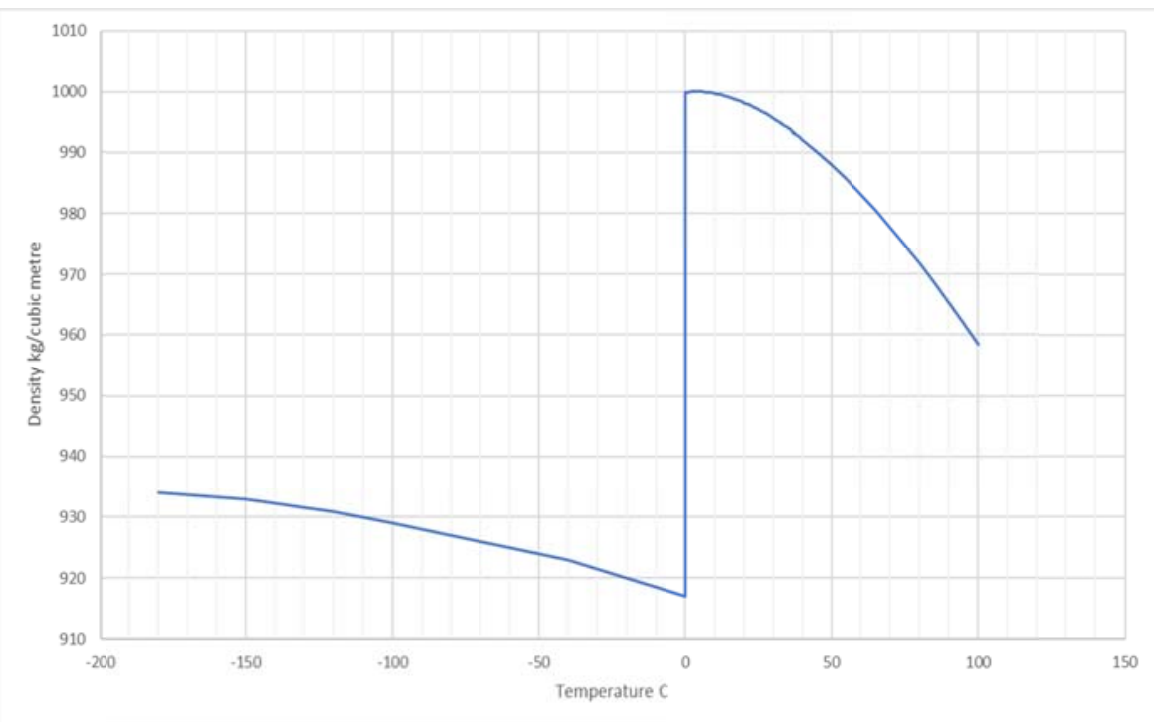

Figure 1. Density of $\mathrm{H}_{2} \mathrm{O}$ at varying temperatures.

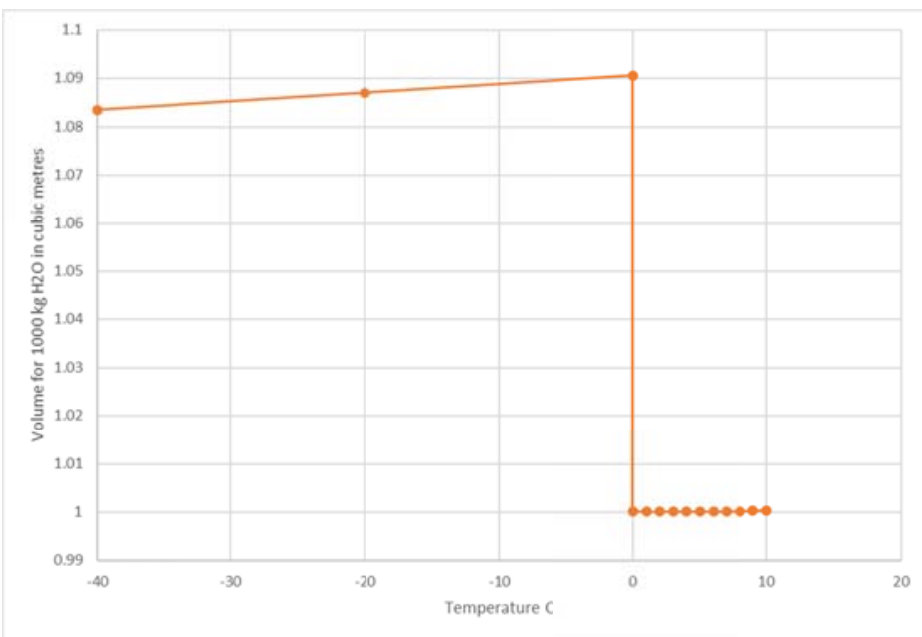

Figure 2. Volume of $1000 \mathrm{~kg}$ of $\mathrm{H}_{2} \mathrm{O}$ at varying temperatures in $\mathrm{m}^{3}$. 


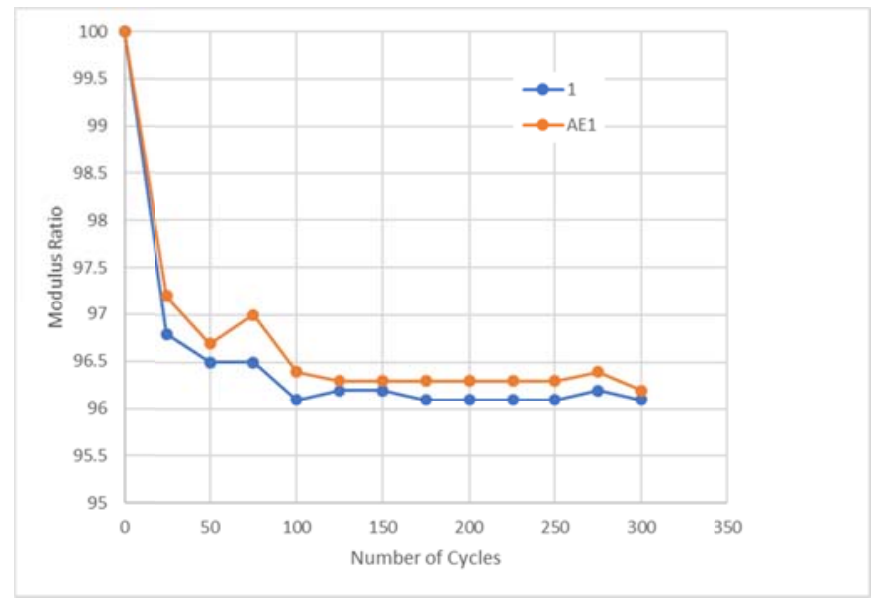

Figure 3. Dynamic modulus ratio for a water to cement ratio of 0.27 .

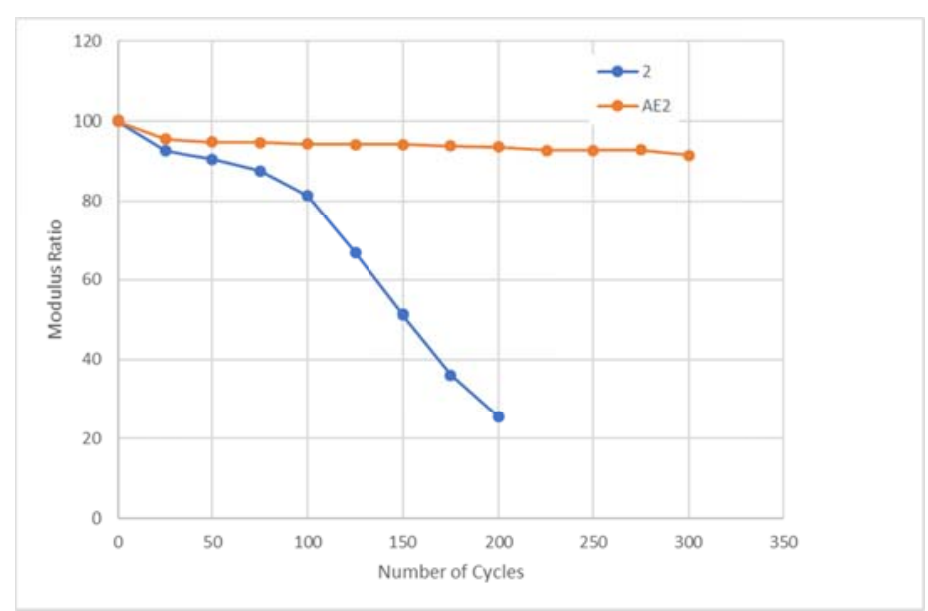

Figure 4. Dynamic modulus ratio for a water to cement ratio of 0.40 .

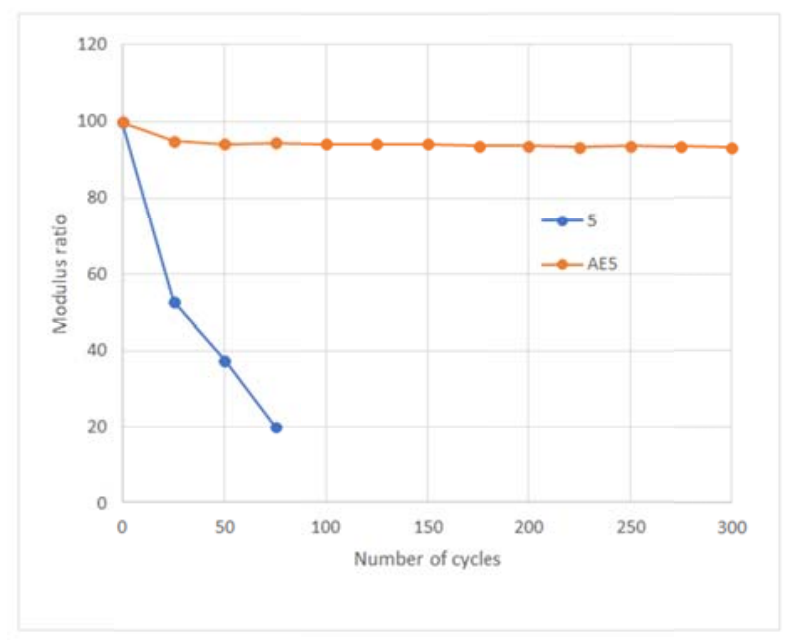

Figure 5. Dynamic modulus ratio for a water to cement ratio of 0.55 . 


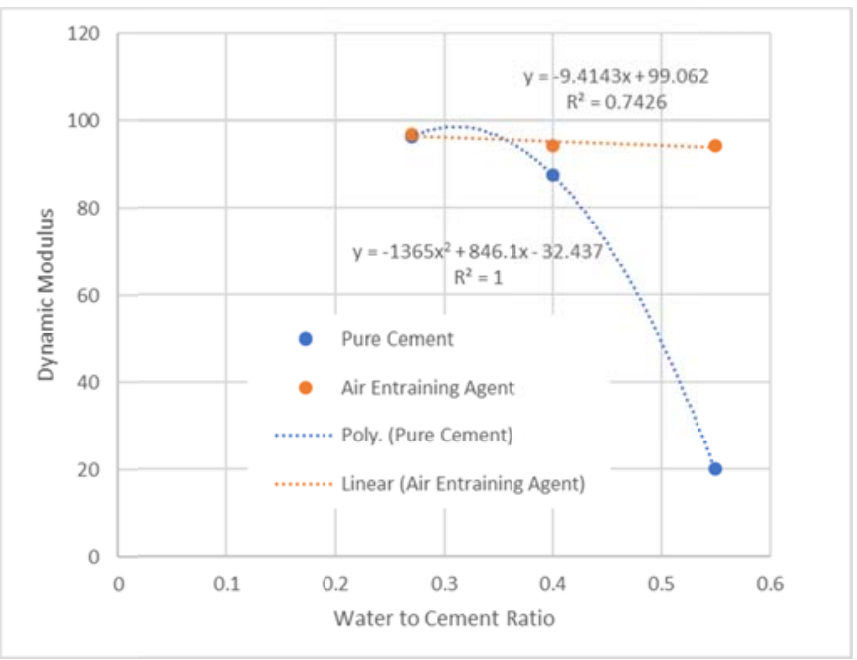

Figure 6. Dynamic modulus ratio for a cycle count of 75 .

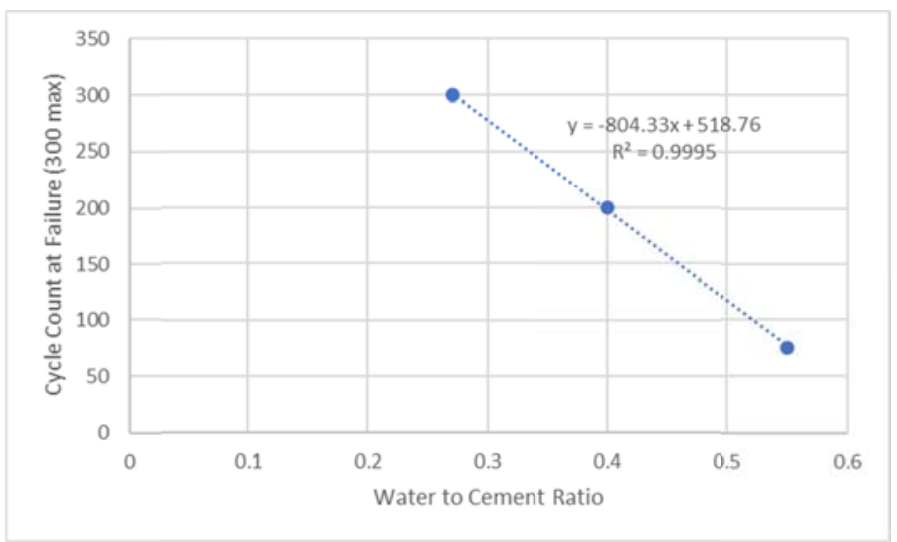

Figure 7. Cycle count at failure against water to cement ratio for plain concrete.

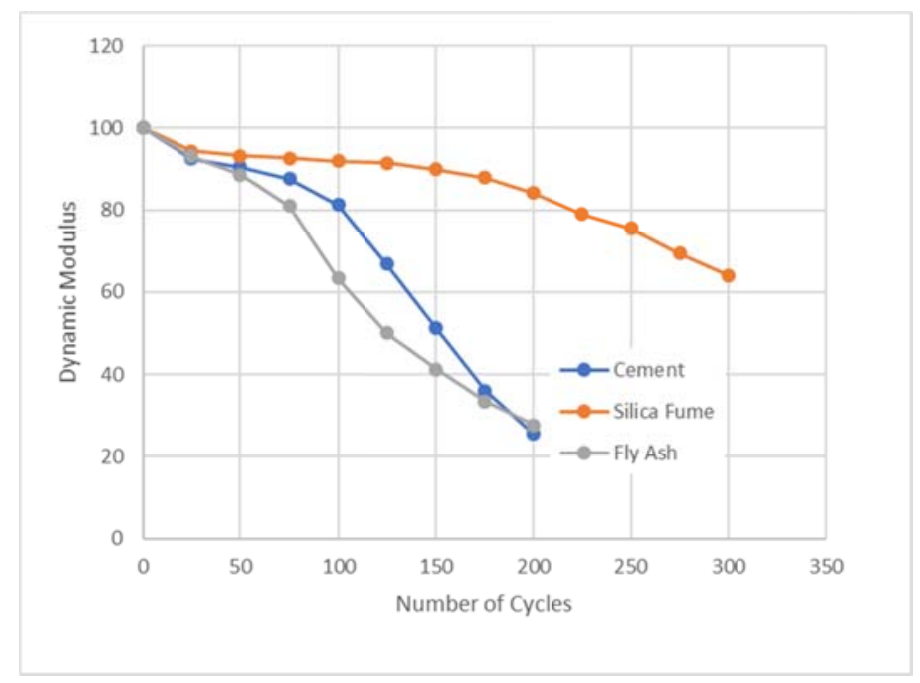

Figure 8. Change in binder for a 0.40 water to cement ratio. 


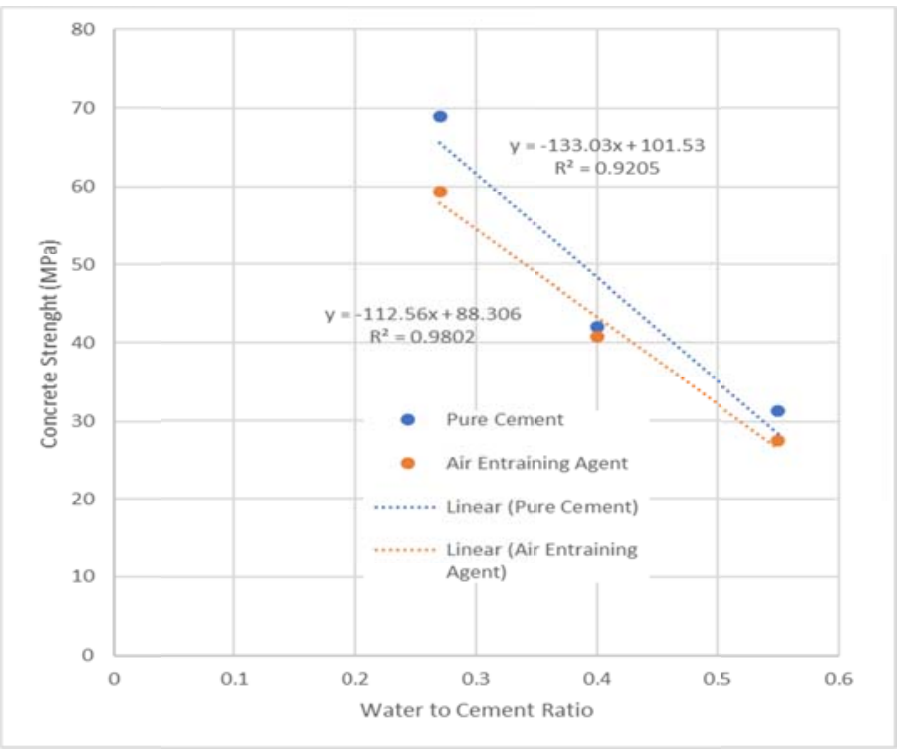

Figure 9. Compressive strength for different water to cement ratios for pure cement and for air entraining agent. 